\title{
A CIÊNCIA HUMBOLDTIANA E A GEOGRAFIA FÍSICA
}

\author{
humboldtian science and physical geography
}

Antonio Carlos Vitte*

\section{Resumo}

Neste artigo defendemos que a geografia física surgiu das reflexões e dos postulados da ciência humboldtiana. Esta formou-se no contexto da Naturphilosophie e no desenvolvimento de novos instrumentos e avancos das ciências exatas, permitindo a construção de um modelo de natureza e superfície da terra baseado no princípio transcendental das leis universais da natureza, materializadas em princípios regionais.

Palavras-chave: Ciência Humboldtiana, Geografia Física, Naturphilosophie, Sensibilidade, Mensuração.

\section{Abstract}

The study argues that the physical geography emerged from the ideas and postulates of science humboldtiana. That formed in the Naturphilosophie and the development of new tools and advances in exact sciences, enabling the construction of a model of nature and the earth's surface based on the principle of transcendental universal laws of nature, material on regional principles.

Key words: Humboldtian Science, Physical Geography, Naturphilosophie, Sensitivity, Measurement.

\section{Resumen}

En este artículo se defiende que la geografía física surgió de las reflexiones y los postulados de la ciencia de Humboldt. Esta se formó en El contexto de la Naturphilosophie por medio del desarrollo de nuevas herramientas y los avances en las ciencias, permitiendo la construcción de un modelo de la naturaleza y la superficie de la tierra, basado en el principio trascendental de las leyes universales de la naturaleza,materializadas en primicias consagrados en la región.

Palabras clave: Ciencia humboldtiana, Geografía física, Naturphilosophie, Sensibilidad, Medición.

(*) Pesquisador do CNPq, Prof. Dr. do Programa de Pós-Graduação em Geografia da Universidade de Campinas - Cx. Postal 6152, CEP: 13083-970, Campinas (SP), Brasil, Tel./Fax (+55 19) 35214570 / 35214552 - vitte@uol.com.br. 


\section{INTRODUÇÃO}

O objetivo desse trabalho é demonstrar que a geografia física moderna possui sua gênese na ciência humboldtiana, que, por sua vez, se desenvolveu a partir de uma relação dialética entre a Naturphilosophie romântica (LENOIR, 1981) e o mecanicismo newtoniano.

Na matriz da Naturphilosophie romântica, podemos localizar as reflexões de Schiller, Schelling, Goethe e Alexander von Humboldt. No entanto, para Georges Gusdorf (1985) é um tanto complexo e perigoso situar Alexander von Humboldt apenas na Naturphilosophie romântica, pois para ele (GUSDORF, 1985) Humboldt está na encruzilhada epistêmica entre Schelling, Schopenhauer e Hegel, pois ao mesmo tempo em que manifesta fortes traços do idealismo romântico, marcado pelo vitalismo, permite a entrada do materialismo schopenhauriano transformado pela metafísica de O mundo como vontade e representação (SCHOPENHAUER, 2005) e pela complexa noção de matéria e ciência que caracterizou a discórdia entre Schopenhauer e Hegel (VITTE, 2007).

A nosso ver, a gênese da geografia física moderna situa-se justamente nesse contexto filosófico e epistemológico, cuja maior preocupação era exatamente qualificar a superfície da Terra, com base em uma enorme quantidade de dados coletados pelos viajantes. É nesse sentido que mais do que descrição ou sistematização de um inventário e sua correspondente hierarquização e distribuição em um espaço geométrico - que caracterizava a superfície da Terra até o século XVIII e sua transição para o XIX (CAPEL, 1995) -, a geografia física representou a possibilidade de reflexão sobre a natureza e a consequente construção simbólica sobre a superfície da Terra e distribuição espacial da natureza nela e suas relações com a cultura.

Essa posição da geografia física frente à construção da modernidade foi garantida por um profundo debate filosófico, cujo amálgama foram a noção de espaço e a crítica radical à ciência mecanicista do século XVII.

Os motores que promoveram a desconstrução da concepção cartesiana-newtoniana de matéria e mecânica da matéria, fundamentos metafísicos para se pensar o espaço e a natureza, foram, por um lado, a Revolução Francesa e, por outro, a filosofia kantiana - que desenvolveu as noções de matéria e movimento nos Primeiros Princípios Metafísicos da Ciência da Natureza, de 1768 (KANT, 1990) e as noções de teleologia da natureza e de experiência estética na Crítica do Juízo de Kant, em 1790 (KANT, 1995). Essas noções foram fundamentais para des-teologizar a natureza e inventar a superfície da Terra e, consequentmente, a geografia física.

\section{NATURPHILOSOPHIE E CIÊNCIA}

As reflexões filosóficas e científicas do século XVIII foram fortemente impregnadas pelo sentimento de Naturphilosophie. Em primeiro lugar, haveria nesse sentimento uma expectativa de explicação global da natureza. Por meio dele, pôde-se entender desde a relação entre fenômenos físicos, químicos, biológicos, etc., como elementos necessariamente interconectados numa explicação do mundo - um kósmos $\square$, até uma compreensão dessa totalidade como, digamos, resultado de uma unidade que ressoaria em domínios interligados - ciência, moral, estética. Em segundo lugar, há uma relação necessária com Kant e, por conseguinte, com Newton. A filosofia de Kant é também um acerto de contas com Newton: trata-se de, entre outras coisas, explicar a física newtoniana através da razão pura - o que não significa, por outro lado, que Kant apenas se mova em torno dessa intenção ou que ele simplesmente corrobore, na sua concepção de razão, com as ideias de Newton. Por isso, é fundamental reconhecer a importância da obra de Kant nesse debate: desde a Crítica da razão pura até os Princípios metafísicos da ciência da natureza e a Crítica do juízo. Em linhas gerais, uma questão que estes textos buscam resolver é a articulação entre mecanismo e finalidade.

Para Lenoir (1981) a questão da teleologia ou finalidade é o conceito central para a noção de organismo e, consequentemente, para a biologia nascente - pensada através de Kant e de sua Crítica do Juízo (1790). 
A finalidade é o produto da causalidade. Para os artefatos humanos, essa compreensão não suscita grande problema, mas, para a natureza, como pensar a finalidade? Ainda mais se considerarmos que os fenômenos naturais estão no tempo e no espaço, submetidos a uma causalidade mecânica. E, no entanto, a partir da experiência devemos construir leis universais (a priori) e leis particulares (empíricas), uma vez que os fenômenos naturais são desigualmente distribuídos na superfície a Terra.

A necessidade que se colocava então era a necessidade de se pensar um sistema de conhecimentos empíricos possíveis, ou seja, um sistema de conhecimento (geografia física) em que, a partir da premissa de uma unidade da natureza, se articulassem o transcendental com o empírico em um movimento, onde a finalidade da natureza fosse o eixo transversal da reflexão.

\section{A QUESTÃO DA SENSIBILIDADE}

O século XVIII pode ser considerado como a idade da sensibilidade (RISKIN, 2002), período em que as críticas às concepções mecanicistas e materialistas desenvolvidas pelos newtonianos se concentravam nas explicações sobre a natureza e os fenômenos naturais dadas por estes.

A discussão sobre a sensibilidade surgiu com o empirismo, doutrina que pregava ser o conhecimento originário da observação e do experimento, o que afetaria a sensação do observador (RISKIN, 2002, p. 1). Para Diderot (apud RISKIN, 2002, p.1), a sensibilidade seria motivada pela capacidade de o observador receber as impressões externas dos objetos. Essa capacidade seria dada pelo movimento destes, que provocaria no observador um sentimento que descreveria a sensação física e emocional em relação ao objeto.

Para Riskin (2002, p. 1), esse seria o gérmen do pensamento do belo e do maravilhoso da natureza, caracterizado por fenômenos singulares da natureza. Desse processo evoluiria o pensamento sobre as emoções do observador perante a beleza natural, sendo a base para o surgimento de paisagem no século XVIII.

De uma sensação física, a sensibilidade evolui para a noção de sensibilidade moral, permitindo já no século XVIII a busca de relações entre o belo natural e o desenvolvimento moral das nações.

A sensibilidade passou a guiar os trabalhos científicos no campo da psicologia, da medicina, da história natural e da geografia física; interferindo nas metodologias de pesquisa, nas epistemologias e nas estratégias de uso das técnicas e experimentos. É assim que, durante a Naturphilosophie alemã, a união entre a sensibilidade e a ciência gerou a concepção de uma visão estética da natureza, que guiou a construção de uma interpretação geográfica da superfície da Terra.

Há, assim, uma relação estreita entre as ciências naturais e o romantismo (CUNNINGHAM E JARDINE, 1990), marcada por uma forte introspecção, reflexão e pela sensibilidade, cimentada pela estreita relação entre arte, natureza e ciência.

A geografia física, surgida no contexto da Naturphilosophie, foi o produto da união entre o sentimentalismo e o empirismo, donde as suas teorias científicas serem o produto de uma relação complexa entre a sensibilidade e o newtonianismo, representada pela ciência humboldtiana.

\section{A CIÊNCIA HUMBOLDTIANA E A GEOGRAFIA FÍSICA}

No século XVIII, as pesquisas nas ciências naturais foram fortemente impulsionadas pela faculdade estética e por uma forte crítica à concepção cartesiana-newtoniana de matéria, o que acarretou uma profunda reforma na filosofia natural, com o surgimento da geografia física.

As pesquisas sobre a natureza e sua qualificação resultaram no século XVIII de uma profunda correlação entre a sensibilidade, a imaginação e a estética, que irão redefinir os experimentos e a mensuração, uma vez que, a partir das influências da filosofia-da-natureza de Schelling (LENOIR, 1981), a natureza foi entendida por meio de uma visão orgânica e pelo vitalismo. 
Nesse contexto, o esforço da ciência humboldtiana, situada na tensão entre a Naturphilosophie romântica e a metafísica, foi o de estabelecer uma visão integral da natureza e ao mesmo tempo leis particulares baseadas na mensuração precisa e no uso da sensibilidade.

A partir de um considerável acúmulo de números e mensurações, a consciência de uma enorme variedade de fenômenos e, acima de tudo, a consciência metafísica da unidade da natureza e da necessidade de se estabelecerem leis transcendentais, ou seja, gerais, Humboldt, fundamentado ontologicamente nas noções de estética da Terceira Crítica (KANT, 1995) e na experiência estética de Schiller, desenvolverá o método da observação da paisagem como postura científica de se registrar a organicidade da natureza e estabelecer as suas relações causais. Motivado pelo vitalismo de Blumembach e de Schelling (RICHARDS, 2002) e pelos avanços na ciência newtoniana, principalmente com os instrumentos de medidas, Humboldt procederá a uma explicação física da natureza, ancorado em uma precisão nas mensurações, no desenvolvimento de inovações gráficas, cartográficas e no estabelecimento de relações causais entre os elementos da natureza e os processos desta, em um contexto regional.

\section{CONSEQUÊNCIAS EPISTEMOLÓGICAS E METODOLÓGICAS DA CIÊNCIA HUMBOLDTIANA PARA A GEOGRAFIA FÍSICA}

\section{A mensuração}

A concepção de mensuração desenvolvida por Humboldt $\square$ que será fundamental para o surgimento da cartografia temática, bem como para vários gráficos, isolinhas e perfis, que, cada qual, demonstrando a noção de organicidade e totalidade da natureza, fundamentado em uma concepção transcendental de natureza $\square$ não pode ser desconectada de sua época nem do contexto filosófico. Assim, não podemos deixar de considerar que os grandes tratados de Alexander von Humboldt foram gestados durante a nova química de Lavoisier, da noção de magnetismo e fluido elétrico de Coulomb, descobertas que alteraram a cognição e a sensibilidade do século XVIII. Obviamente que o caldo que impregnou essas descobertas foi a Revolução Francesa e sua estética do terror.

É nesse contexto de Naturphilosophie e construção de uma nova metafísica da natureza que a physique du monde de Humboldt procurou reavaliar criticamente o conceito global de interação das forças físicas da natureza.

Para Humboldt, as ciências naturais não deveriam ficar presas apenas a conceitos antigos e concepções desenraizadas da empiria. A ciência deveria fazer uso de gráficos, linguagens simbólicas universais, de tal maneira que pudessem expressar resultados confiáveis.

Em suas pesquisas de geologia, Humboldt adotou a química e a termometria de Lavoisier, as técnicas de mensuração dos ângulos, desenvolvidas por Coulomb. Durante a preparação para a viagem à América, ele comprou instrumentos modernos e de precisão em Viena e Paris (DETTELBACH, 1990).

Para Humboldt, o uso de instrumentos precisos e uma mensuração precisa demandavam o uso de uma linguagem precisa e uma sensibilidade especial para o registro da organicidade-totalidade da natureza. Para isso, o trabalho geográfico necessitava de um amplo realismo matemático com equações algébricas desenvolvidas, criações gráficas e cartográficas, de tal forma que se pudesse "transcendentalizar" a existência de substâncias puras em compostos, sempre utilizando a sensibilidade para a construção de arquétipos da natureza.

A partir do cânone regional, a diversidade da natureza é transcendentalizada e, conjuntamente com a experiência estética, as leis universais poderiam ser construídas, o que explicaria a distribuição geográfica das paisagens naturais. Isso será fundamental para o desenvolvimento da cartografia temática em Humboldt e da noção de perfil topogeográfico, como síntese da relação entre o particular e o universal; assim como essa matriz estética será importante para a construção da noção de unidade regional da natureza, cuja síntese pode ser representada pela pintura de paisagem. 
O que perpassa a ciência humboldtiana, da qual a geografia física é a grande herdeira, é a crença ontológica no conceito de espaço, que se manifesta na noção de espacialidade, criada por Humboldt, de acordo com a qual a noção de paisagem será a síntese do transcendental, manifesta em princípios mecânicos e estéticos.

Para Humboldt, um instrumento de pesquisa tem a finalidade de, ao mensurar, influenciar a sensibilidade, e, a partir disso, organizar a matéria da natureza, que para Humboldt é uma força vital.

A crença no vitalismo levou Humboldt a utilizar uma série de instrumentos, desde aqueles que detectavam pequenas mudanças químicas até o barômetro. Para ele, isso era necessário para “[...] analyze the total impression made by nature on our organs" (LANGE E JAHN, 1973, p. 584).

Assim, os gráficos expressavam as mensurações precisas e procuravam representar a realidade física, com que a natureza se manifestava ao observador. Ou seja, marcado por uma forte sensibilidade, o observador poderia registrar as forças imateriais da natureza que plasmam a paisagem.

\section{Mapeamentos e construções gráficas}

Os mapas, como o de isolinhas, talvez o mais famoso gráfico de Humboldt, expressavam justamente o testemunho do poder e da precisão da observação da natureza. Para Humboldt, um gráfico ou um mapa possuía o poder de comunicar a outros homens a beleza da natureza, tendo também um efeito educativo (RICOTTA, 2003).

A concepção humboldtiana fundamentava-se na premissa de que a natureza era dinâmica e as variáveis físicas eram irredutíveis, pois seriam o produto simultâneo de várias causas físicas. As isotermas, por exemplo, apesar dos artifícios matemáticos, das mensurações precisas, eram sempre irredutíveis, pois eram fenômenos físicos, não predeterminados matematicamente:

Temperature and magnetism are not like those phenomena which, derived from a single cause or a central force, can ber freed of the influence of disturbing causes by restricting attention to the mean results of a great number of observations, in which these foreign effects reciprocally counteract and destroy one another. The distribution of heat, like the declination and inclination of the compass needle or the intensity of magnetic force, is essentially conditioned by location, composition of the soil, by the proper ability of the earth's surface to radiate heat. One must beware of eliminating what is sought; one must not classify as foreign and disturbing causes those upon which the most important phenomena in the distribution and the more rapid or slow development of organic life essentially depend. (HUMBOLDT, 1817, p. 462; In: FELDMANN, 1990, p. 164-177).

Segundo Dettelbach (1990), Humboldt desenvolveu o método das isolinhas baseado nos trabalhos do astrônomo e cosmógrafo, Tobias Meyer (1723-1762), professor em Göttingen, muito preocupado com a distribuição do calor na superfície da Terra. Dessa preocupação, Meyer desenvolveu baseado em equações de trigonometria, com coeficiente indeterminado, a curva de distribuição do calor solar sobre a superfície da Terra, a partir de uma relação entre o calor solar e o magnetismo da Terra.

O cálculo de Meyer era essencialmente matemático e geométrico, o que incorria em falta de precisão, o que levou Humboldt a se preocupar com as medidas geodésicas da Terra e a se preocupar com a construção de instrumentos mais precisos.

Para Dettelbach (1990), Humboldt aperfeiçoou o método das isolinhas de Meyer, na medida em que utilizou uma série de aparelhos para mensurar o calor solar e correlacionou-o com a distribuição da vegetação no globo, aperfeiçoada com uma tabela e gráficos descritivos que trabalhavam com o princípio da correlação espacial. Essa correlação espacial foi alcançada metodologicamente na medida em que Humboldt considerou em um mesmo meridiano uma família de uma flora local e observou a sua variação em frações ao longo do paralelo do equador. Considerou que a vegetação não apresentaria variações bruscas, como a temperatura ou o magnetismo; e, em pontos fixos do gráfico, considerou as possibilidades de variações entre a vegetação e seu ambiente. 


\section{A PINTURA DE PAISAGEM: instrumentalização-empiricização da totalidade e representação ontológica da natureza em Alexander von Humboldt}

Surgida nos séculos XV e XVI como uma forma de ver o mundo externo, a ideia de paisagem ainda é para os dias atuais uma expressão visual derivada do humanismo renascentista, conceito chave no construto de espaço (COSGROVE, 1985 p. 46).

A representação da paisagem e a sua ligação com a apropriação do espaço ocorrem através das novas técnicas cartográficas decorrentes das novas demandas trazidas pela expansão ultramarina e o comercio mercantilista. Na pintura e no desenho paisagístico de jardim foi atingida a concepção visual. Do ponto de vista ideológico, a pesquisa e a fabricação de mapas de ordenação gráfica alcançaram o controle e dominação sobre espaço como um absoluto, entidade objetiva, transformando-o em propriedade do indivíduo ou do Estado (COSGROVE, 1985 p.46).

Toda essa ordenação e desenho têm uma técnica óptica apoiada sobre a perspectiva linear baseada na geometria euclidiana. No caso da paisagem, a técnica foi óptica, perspectiva linear, mas os princípios aprendidos foram idênticos aos de arquitetura, levantamento, mapas de tomada de artilharia e ciência (COSGROVE, 1985 p.46). Esses elementos se referem ao início das representações do período retratado, pois a paisagem não é apenas uma matematização da natureza. Durante sua história, a representação e a forma de vermos vão sendo repensadas por filósofos e cientistas-naturalistas.

Retomando a importância da geometria euclidiana, temos a sua aplicação na representação espacial tridimensional representada teórica e tecnicamente através de um único ponto, o da visão. As figuras 1 e 2 representam o entendimento dessa forma de ver geometricamente. Esse movimento, apesar da sua ênfase nos textos clássicos, revolucionou a apreensão espacial no campo das artes plásticas e visuais. Tanto na pintura, escultura e arquitetura quanto na geografia e na cosmologia $\square$ todas envolvidas com o espaço e suas implicações $\square$, a geometria foi a base por meio da qual suas forma e estrutura foram determinadas (COSGROVE, 1985 p.47). A importância dessas representações está no fato de tornar algo tridimensional em bidimensional, uma vez que na representação a paisagem tridimensional é transposta ao "papel", cujo plano é bidimensional. Trata-se de uma tentativa de não distorcer, ou com a menor distorção possível do objeto, a representação do real, do que é visto.

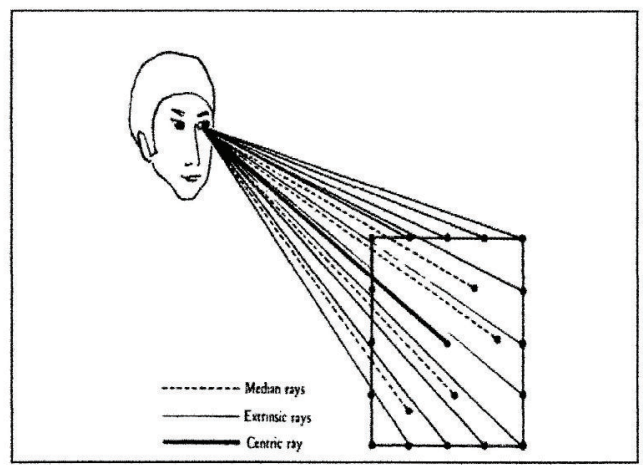

Figura 1: O Triângulo Visual descrito por Alberti Fonte: Denis Cosgrove, 1985 p.47.

Na teoria apresentada na figura 1 e aplicada à figura 2, notamos uma leitura realizada através do emprego "pirâmide visual", que se obtém como consequência de formas e posição no espaço mostrado relativa e não absolutamente. Tais formas dos objetos no espaço e das figuras geométricas variam de acordo com a distância e o ângulo de visão, cujos raios originam-se do olho em si, confirmando assim a sua soberania no centro do mundo visual. Essa técnica tornou-se fundamental para as representações realistas planas do mundo externo, pois, é através da perspectiva que o artista 
estabelece uma composição dos eventos descritos e determinados pela forma como o observador vê o mundo (o ponto de vista) (COSGROVE, 1985 p. 47).

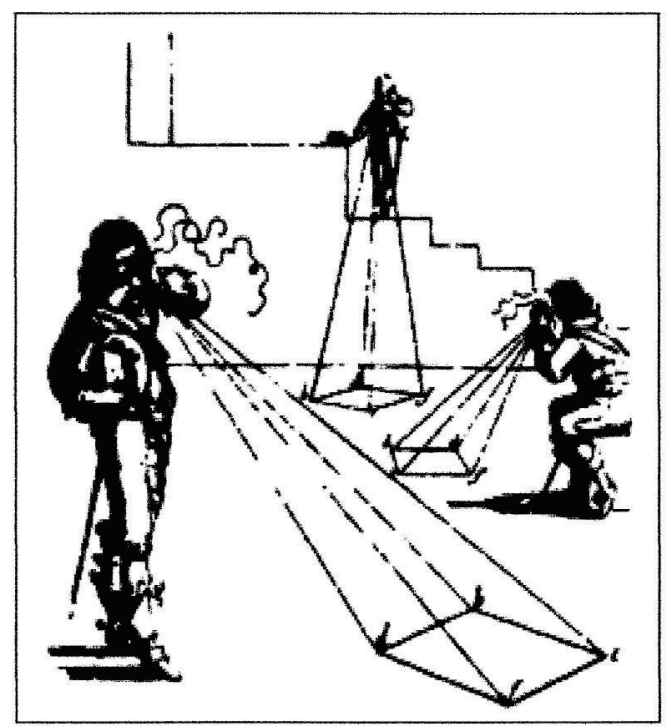

Figura 2: Seleção areal a partir da visão em perspectiva. Fonte: Denis Cosgrove, 1985, p.48

A perspectiva geométrica deu suporte ao princípio da construção das paisagens, construção essa que determina e delimita as fronteiras ou a localização dos elementos geográficos em mapas e que auxiliou as representações pictóricas, ambas interligadas na geografia. Essa mesma perspectiva vem garantir a certeza da reprodução do mundo real, seja pelo artista ou pelo geógrafo.

Para além da questão das técnicas específicas, há também metodologias semelhantes entre a paisagem na pintura e na geografia, que têm geógrafos autorizados a adotar inconscientemente algo da ideologia visual integrante da ideia de paisagem (COSGROVE, 1985 p.57). A paisagem, porém, não se restringe apenas a projeções e perspectivas geométricas, esse ponto é apenas mais um na vasta contribuição da formação de tão importante conceito para a geografia.

Depois de retratarmos brevemente a base da representação à luz da geometria, iremos agora nos aproximar mais da relação entre as artes plásticas e a geografia, tendo como figura central Alexander von Humboldt. Suas obras constituem uma parte importante da geografia e da ciência moderna, pois contribuíram para o pensamento humanista e, em especial, ao pensamento ecológico e geofísico.

Dentre as principais contribuições de sua obra, as que mais se destacam são as suas observações científicas e ideias sobre a natureza, bem como as suas reflexões sobre a paisagem e estética, enunciadas pela primeira vez nas obras, Aspectos da Natureza e em Narrativa Pessoal das Viagens para as Regiões equinociais do Novo Mundo e, mais tarde foram elaboradas em Cosmos. (BUNKSE, 1981, p. 131)

Humboldt é de grande importância para nossos estudos, como já dito acima, mas devemos ressaltar a contribuição para a ciência com seu trabalho empírico e todo seu método. Sua obra não é apenas uma enciclopédia do mundo natural, pois ela apresenta um rigor cientifico nas suas descrições, além do cuidado com a escrita, uma "herança" do Romantismo alemão, além de usar a pintura para poder representar tudo que suas observações empíricas lhe proporcionam. Segundo Humboldt (apud BUNKSE, 1981, p. 133), o grande destaque dado às representações da paisagem tem como finalidade:

In order to depict nature in it's exalted sublimity, we must not well exclusively on its external manifestations, but we must trace its image, reflected in the mind of man, at one time filling the dreamy 
land of physical myths with forms of grace and beauty, and at another developing the noble germ of artistic creation.

Abaixo vemos duas pinturas que retratam Tequedama, na então Nova Granada (atual Colômbia), uma atribuída a Alexander von Humboldt (figura 3) e outra ao pintor estadunidense Frederic Edwin Church (figura 4), pintor este que refez parte do trajeto pelos trópicos, devido a influência de Humboldt.

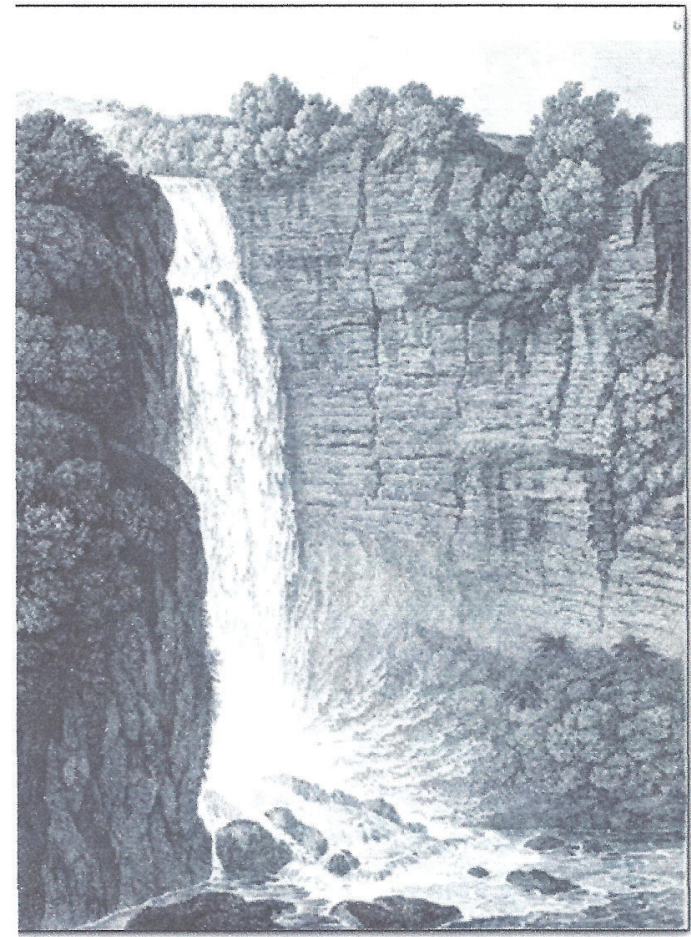

Figura 3: Alexander von Humboldt, Tequendama (1810) Fonte: Frank Baron, 2005.

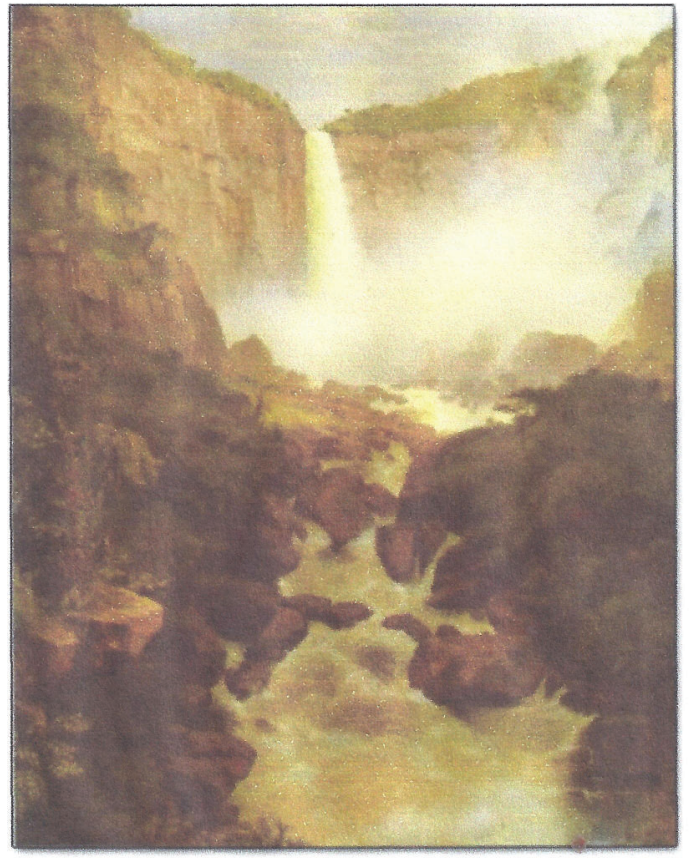

Figura 4: Church, Falls of the Tequendama near Bogotá, New Granada (1864) Fonte: Frank Baron, 2005.

Existia uma ideia unificada entre arte e paisagem que, para Humboldt, era um desenvolvimento concomitante desta que ele apresenta em seus trabalhos, onde o sentido e o objetivo existiam lado a lado. Esta visão unificada era uma abordagem do mundo fenomenal inteiramente em harmonia com as percepções artísticas da paisagem (BUNKSE, 1981, p. 137).

Agregado a essa ideia, tem-se o pensamento kantiano como parte do entendimento sobre os diferentes aspectos da natureza caracterizado pelas sensações do belo e do sublime formados pela mente humana. Humboldt associava aos seus estudos a contemplação da natureza, que apontava para a arte e a ciência, e transformava-se num esforço grandioso em demonstrar as tentativas de delimitação da fisionomia da paisagem, não apenas como um todo, mas também considerando as características particulares de cada planta. Isso reflete a noção de prazer estético e que tal prazer varia com as diferentes fisionomias de paisagem (BUNKSE, 1981, p.139). acima:

A passagem a seguir do Cosmos, citada por Bunkse (1981, p.138), passa a ideia menconada

In the uniform plain bounded only by a distant horizon, where the lowly heather, the cistus, or waving grasses, deck the soil; on the ocean shore, where the waves, softly rippling over the beach, leave a track, green with the weeds of the sea; everywhere, the mind is penetrated by the same sense of the grandeur and vast expanse of nature, revealing to the soul, by a mysterious inspiration, the existence of laws that regulate the forces of the universe. 
Nesta explicação sobre o sentimento de paisagem - apresentado com características definidas -, Alexander von Humboldt afirma que a impressão produzida pela paisagem é determinada por meio das particularidades desta. Havia o pressuposto que o pintor tinha uma missão, a de captar elementos que são essenciais de uma paisagem com o intuito de proporcionar um misto de sensação e prazer no imaginário humano. No entanto, para ele a percepção ambiental não se dava por meio de respostas a estímulos naturais na mente, mas sim mediante uma interação mútua entre espírito e matéria, interação complexa e sutil. Existia, entre a intuição humana e a racionalidade, uma complexa interação que determinava o lugar "retratado" e, no que diz respeito aos pintores de paisagem, essa mesma interação é o que determinava os poderes artísticos (BUNKSE, 1981, p.140).

Em "Narrativas Pessoais", Alexander von Humboldt (apud BUNKSE, 1981, p.141) diz que: "As grandes concepções da pintura da paisagem, mais ou menos inspiradas num ramo da poesia da natureza, devem-se ao poder criativo da mente - tal como o próprio homem - e as faculdades imaginativas com que ele é dotado, independente do local" (tradução nossa).

$\mathrm{Na}$ "construção" da ideia de paisagem, a inserção dos conceitos como a forma de olhar a natureza, de apreciar o belo e sublime, vem somar com a representação geométrica para pintura de paisagem e formação do conceito para as ciências geográficas. O sublime passa a ser padrão estético da "forma de olhar" e representar o mundo externo.

Indo mais fundo no detalhamento da paisagem, Humboldt vai estudar e detalhar o comportamento da luz que incide sobre a paisagem, em especial nos trópicos. Formulou detalhadas descrições e mostrou medições científicas das mudanças na qualidade da luz, nas suas cores e tonalidades, que ocorrem com as mudanças de altitude, distância, umidade, e hora do dia. Dentre esses descrições, utilizou observações de propriedades físicas da luz em relação à capacidade de ver objetos distantes e, também, levando em conta a influência da atmosfera nessa capacidade de ver, o efeito refratado da luz nos diferentes tipos de superfícies (BUNKSE, 1981, p.144).

Uma passagem da obra Narrativas Pessoais, também presente no texto de Bunkse (1981, p. 144), retrata bem a importância dada por Alexander von Humboldt em estudos específicos, como a refração da luz, na composição da descrição, observação e ideia de paisagem:

Notwithstanding the elevation of the spot, the sky is generally less blue at Caraccas [sic] than at Cumana. The aqueous vapour is less perfectly dissolved; and here, as in our climates, a greater diffusion of light diminishes the intensity of the aerial colour, by introducing white into the blue of the air. This intensity, measured with the cyanometer of Saussure [instrument that measures degrees of blueness], was found from November to January generally $18^{\circ}$, never above $20^{\circ}[\ldots]$ in the village of Caraccas [sic]. [...] the wind of Petare sometimes contributes singularly to give a pale tint to the celestial vault. On the 22nd of January the blue of the sky was at noon in the zenith feebler than I ever saw it in the torrid zone. It corresponded only to $12^{\circ}$ of the cyanometer. The atmosphere was then remarkably transparent, without clouds, and of extraordinary dryness. The moment the wind of Petare ceased, the blue colour rose at the zenith as high as $16^{\circ}$.

Nessas observações fundamentadas nas características da superfície física dos trópicos, Humboldt chama a atenção dos artistas para a importância da atmosfera na elaboração da pintura de paisagem, pois o estudo cuidadoso da atmosfera pode demonstrar com mais exatidão e proporcionar um melhor entendimento sobre a localidade em estudo. Partindo dessa importância do estudo atmosférico, Humboldt destaca a fonte de luz como uma curiosidade sua sobre o "aperfeiçoamento" da estética da paisagem. Nos trópicos "o sol não apenas clareia", mas também dá cores aos objetos, ao envolvê-los em uma fina "fumaça" de vapor, que, sem alterar a transparência do ar, tornas as tonalidades mais harmoniosas, suaviza os efeitos da luz, e difunde sobre a natureza que acalma que se reflete em nossas almas." Humboldt foi uma das primeiras pessoas a gravar este fenômeno de luz peculiar aos trópicos (BUNKSE, 1981 p.145). 
O trabalho que primeiro traz todos esses elementos de análise para a construção da visão, demonstração e representação do mundo físico tropical é o Essai sur la géographie des plantes (Ensaio sobre a geografia das plantas), obra esta publicada em 1807, na França. Segundo Malcolm Nicolson (1990, p. 172), esta obra teve como objetivo central despertar a atenção dos filósofos naturalistas para a exuberante natureza tropical e para os fenômenos que a compõem. Para Humboldt, a Natureza passou a ser uma unidade holística. O equilíbrio geral, que reina entre os distúrbios e a aparente confusão, é o resultado de uma infinidade de forças mecânicas e atrações químicas equilibrando-se mutuamente. Mesmo que cada série de fatos deva ser considerada separadamente para identificar uma determinada lei, o estudo da natureza, que é o maior problema de la physique générale, exige a congregação de todas as formas de conhecimento que lidam com as modificações da matéria. (NICOLSON, 1990 p.172)

Podemos encontrar um grande exemplo em Essai, o Tableu physique des Andes et pays voisins. Nele, Humboldt elaborou uma figura de tamanho grande que consistia no perfil transversal dos Andes na latitude de Chimborazo, abrangendo uma "linha" que vem do Atlântico para o Pacífico. Nesta representação são mapeados ou tabulados, em latim, a localização de plantas e sua altitude (onde inicia e termina) e o local onde vivem os animais desta região. Também podemos encontrar descrições sobre o cultivo agrícola, geologia, meteorologia, ou seja, uma ampla variedade de dados físicos. O objetivo era dar, em uma única ilustração, uma completa impressão de uma região natural a "régions équinoctiales" da "América do Sul." (NICOLSON, 1990 p. 173-178)

De acordo com Margot Faak, essa seção transversal do Chimborazo era a mais ousada experiência, imaginada e elaborada por Humboldt, na apresentação gráfica de dados de cunho científico. A imagem mostra a concepção das instalações geográficas e reflete o esforço para mostrar a unidade, diversidade e interdependência da natureza.

Neste trabalho, Humboldt conseguiu contemplar a arte, em sua representação da paisagem e ciência, com seus dados empíricos, proporcionando um desenvolvimento mútuo de ambos os conhecimentos. Ou seja, duas abordagens de natureza, sendo uma complementar da outra, demonstrando o que naquele período era comum: a indissociabilidade da arte e da ciência.

A contribuição desse grande cientista naturalista não para por aí, pois durante seus trabalhos de campo, onde realizava uma imensa coleta de dados, ele fazia uso intensivo de instrumentos a fim de obter com o maior rigor possível parâmetros científicos, onde exploradores anteriores tinham realizado mera descrição. (NICOLSON, 1990 p. 181)

Lançando mão de todo aparato técnico e instrumental que dispunha na época, Alexander von Humboldt mensurou praticamente tudo o que fosse possível mensurar. Assim sendo, pôde levantar diversos pontos com grandes e variadas quantidades de dados, criando sítios que, ao sem comparados, formavam linhas que representavam o mesmo valor por onde elas "passavam". Essas correlações deveriam, era esperado, colaborar no discernimento das leis que regem a distribuição da vegetação. Para facilitar este trabalho, Humboldt foi pioneiro na técnica cartográfica de isolinhas 7). (NICOLSON, 1990 p.181).

\section{CONSIDERAÇÕES FINAIS}

Após a discussão apresentada neste texto, acompanhada das imagens do autor, percebemos que a contribuição de Alexander von Humboldt não fica restrita à descrição de suas experiências ou a uma única área do conhecimento, ela se estende para além da arte pictórica, da história natural, da geografia e geofísica. Isso se explica porque ele buscou entender a concepção do funcionamento da natureza como um todo e a paisagem, nesse sentido, concorre para delimitar esse todo. Ela nasce a partir das concepções de Humboldt "de que existe uma harmonia na ordem natural e que a natureza manifesta-se diferenciada na superfície terrestre em função de como ocorre entre os seus elementos" (VITTE, 2007b, p. 83). 
Humboldt acreditava que a grande diversidade de perspectivas, que ele adquiria através da sua exploração científica, acabaria por contribuir para o entendimento da unidade na natureza. (Frank Baron, 2005 p.12)

Guiado pelo vitalismo e pelas reflexões sobre o influxo material de Blumembach, pela noção de orgânico de Kielmeyer, assim como pela noção kantiana de teleologia da natureza e de organismo, Humboldt desenvolveu a noção de que há um vitalismo na natureza, uma enteléquia que conduz a relações e conexões nas mais diferentes escalas entre as entidades e que se manifesta na paisagem. A isso Humboldt chamará inicialmente de "fisiogonomia" da paisagem, que permite não apenas o conhecimento mecânico da natureza, da paisagem, que é a fisiologia, mas também a descoberta de uma arqueologia da natureza, de tempos acumulados. Essa noção de "fisiogonomia" da paisagem evoluirá para os conceitos de fisiologia e de geoesfera, que serão as bases de construção da moderna geografia física e que tanto influenciará Charles Darwin.

A ciência humboldtiana apresenta várias faces, Entre elas destaca-se o projeto estético da Naturphilosophie, por meio da qual definiu uma concepção teleológica, holística segundo a qual a natureza e a cultura humana estão profundamente interligadas.

Ao mesmo tempo, Humboldt garantiu espaço para o surgimento da geografia física, guiada não só por um senso estético, mas também por um profundo conhecimento causal de relações entre os fenômenos; além de demonstrar que a geoesfera é o produto de múltiplas causas e interações, redefinindo assim a lei da causalidade nos estudos geográficos. Humboldt foi o responsável tanto pela criação da geografia física como pela introdução da história da natureza nessa mesma geografia física, na medida em que considerou que vários climas se sucedem ao longo do tempo e deixam suas marcas nos estratos, o que permite, por meio da mensuração, da observação e da correlação espacial, reconstruir a história da natureza em paleoespaços.

\section{REFERÊNCIA BIBLIOGRÁFICA}

BARON, Frank. From Alexander von Humboldt to Frederic Edwin Church: voyages of scientific exploration and creativity. Internationale Zeitschrift für Humboldt Studien, HiN vol. VI. n 10,2005. Disponível em $<$ http://www.uni-potsdam.de/u/romanistik/humboldt/hin/pdf/hin10/baron.pdf $>$. Acessado em: 10/06/2009. BUNKSE, Edmunds V. Humboldt and an aesthetic tradition in geography. Geographical Review, vol. 71, $\mathrm{n}^{\circ}$. 2, 1981, p. 127-146. Disponível em: <http://www.jstor.org/stable/214183>. Acessado em: 10/06/2009.

CAPEL, Horácio. Ramas em el árbol de La ciência. Geografía, Fisica e Historia Natural en lãs expediciones náuticas del siglo XVIII. In: TORRE, A.R.D; MALO, T.; FERNANDEZ, D.P. (orgs) De la ciência ilustrada a la ciencia romántica. Madrid: Doce Calles, 1995, p.503-537.

COSGROVE, Denis. Prospect, perspective and the evolution of the landscape idea. Transactions of the Institute of British Geographers, New Series, vol. 10, n. 1, 1985, p. 45-62. Disponível em: <http://www. jstor.org/stable/622249>. Acessado em: 10/06/2009.

CUNNINGHAM, Andrew; JARDINE, Nichols. (eds.) Romanticism and the sciences. Cambridge and New York: Cambridge University Press, 1990.

DETTELBACH, Martin. Romanticism and administration. In: CUNNINGHAM, A.; JARDINE, N. (eds.) Romanticism and the sciences. Cambridge and New York: Cambridge University Press, 1990, p. 193-207. FAAK, Margot. Alexander von Humboldt, Reise auf dem Rio Magdalena, durch die Anden und Mexico. In: Alexander von Humboldt: Everything is interconnected, vol. 1, p. 358. Disponível em: <http://www. avhumboldt.net/index.php?page=149>. Acessado em: 30/10/2009.

FELDMAN, Thomas. Late Enlightenment Meteorology. In: HEILBRON, T.; FRANGSMAYER, T.; RIDER, R. (eds.) Quantifying Spirit. Berkeley: University of California Press, 1990, p.164-177.

GUSDORF, Georges. Le savoir romantique de la nature. Paris, Payot, 1985.

KANT, Immanuel. Princípios Metafísicos da Ciência da Natureza. Porto: Edições 70, 1990.

KANT, Immanuel. Crítica da Faculdade de Julgar. Rio de Janeiro: Forense Universitária, 1995. 
LANGE, Frank. e JAHN, Ian. (eds.) Die Jugendbriefe Alexander von Humboldts. Berlin: Akademie, 1973, p. 584-657.

LENOIR, Timothy. The Göttingen School and the Developement of Transcendental Naturphilosophie in the Romantic Era. In: COLEMAN, W. e LIMOGES, C. (orgs). Studies in History of Biology. Baltimore and London: John Hopkins University Press, 1981, p. 111 a 205.

NICOLSON, Malcolm. Alexander von Humboldt and the geography of vegetation. In: CUNNINGHAM, A.; JARDINE, N. (eds.) Romanticism and the sciences. Cambridge University Press. Cambrigde, 1990, p. $169-188$.

RICHARDS, Robert J. The Romantic Conception of Life. Chicago and London: Chicago University Press, 2002.

RICOTTA, Lúcia. Natureza, Ciência e Estética em Alexander von Humboldt. Rio de Janeiro: Mauad, 2003. RISKIN, Jensen. Science in the Age of Sensibility. Chicago and London: Chicago University Press, 2002. SCHOPENHAUER, Artur. O Mundo como Vontade e Representação. São Paulo: Editora da Unesp, 2005. VITTE, Antonio C. Da metafísica da natureza à gênese da geografia física moderna. In: VITTE, Antonio C. (org.) Contribuições à História e à Epistemologia da Geografia. Rio de Janeiro: Bertrand Brasil, 2007, p. 11-47.

VITTE, Antonio C. Influência da Estética Kantiana na Gênese da Geografia Física. Anais VII ANPEGE. Rio de Janeiro, Anais, CD-ROOM, UFF, p. 1-10, 2007a .

VITTE, Antonio C. A Categoria Paisagem e o Desenvolvimento da Geografia Física. Mercator, vol. 6, n. 11, 2007b, p. 11-32. 